\title{
Developing university-business cooperation through work-integrated learning
}

\section{Giselle Camille Rampersad}

Flinders University, Sturt Rd, Bedford Park SA 5042, Australia

Email: giselle.rampersad@flinders.edu.au

\begin{abstract}
While university-business cooperation (UBC) is predominantly focused on commercialisation involving university staff and firms, the area of work-integrated learning (WIL) including students is increasing in prominence. WIL is an intrinsic component and catalyst for broader UBC. It has also been widely recognised as fundamental in the education arena to equip graduates with the required industry experience to innovate successfully. Despite its importance, the UBC literature places limited attention on WIL. Cooperation between university and business at the organisational level of relevant institutions as well as the individual level of participating managers and students is fundamental. Focusing on the student at the interface of UBC, this study contributes a framework for developing UBC through WIL. Managerial implications are discussed for universities and businesses engaged in UBC.
\end{abstract}

Keywords: university-business cooperation; UBC; technology transfer; work-integrated learning; WIL; technology management.

Reference to this paper should be made as follows: Rampersad, G.C. (2015) 'Developing university-business cooperation through work-integrated learning', Int. J. Technology Management, Vol. 68, Nos. 3/4, pp.203-227.

Biographical notes: Giselle Camille Rampersad is a Senior Lecturer in Innovation at Flinders University, Australia. She coordinates a Bachelor degree in Design and Technology Innovation and manages the industry placement programme. She obtained her $\mathrm{PhD}$ in Innovation and Technology Management (University of Adelaide, Australia), MSc in E-Business and Internet Systems (Durham University, UK) and BSc in Management Studies (University of the West Indies, Trinidad and Tobago). Her current research interests include innovation and technology management. She has authored several scholarly publications including in the Journal of Engineering and Technology Management, Industrial Marketing Management, Journal of Computer Information Systems and International Journal of Technology Transfer and Commercialisation.

\section{Introduction}

The area of university-business cooperation (UBC) is growing in prominence. This is due to a range of factors including decreased government science and technology budgets in times of crisis (Makkonnen, 2013), commercialisation as an important component of universities (D'Este and Patel, 2007; Perkmann et al., 2013), growing community scepticism towards universities and the need for universities to participate in regional 
economic development (Lee, 1996) and to contribute towards building dynamic national innovation systems (Motohashi, 2013). Otherwise termed university-industry collaboration (Lee, 1996), triple helix of university-industry-government relations (Etzkowitz and Leydesdorff, 2000), university-industry technology transfer (Siegel et al., 2001), or university technology transfer (Harmon et al., 1997), it involves partnerships between university, business and government to achieve shared innovation outcomes (Rampersad et al., 2009) and can take many forms. These include consulting, new firm spinoffs and technology licensing (Etzkowitz and Leydesdorff, 1998; Harmon et al., 1997).

While much research has focused on various models of UBC, limited research focuses on the critical role of the student at the interface of UBC. Astebro et al. (2011) argue that the majority of research on UBC focuses on faculty spinoffs based on intellectual property from university research funding and ignores the large part of entrepreneurial activity, particularly by students, stemming from universities that never get recorded. Similarly, Stephan (2001) emphasises that while much research has been done about the impact of technology transfer on openness in science and the trend from basic to applied research, little research has focused on the critical role of the student and the impact of technology transfer on education and vice versa. She provides an important example of the interface between students and UBC illustrating how industry engagement between Grinnell College and Bell Laboratories in 1948-49, exposed an undergraduate student, Robert Noyce, to Bell's transistors resulting in Noyce doing further research in the area, co-inventing the integrated circuit and going on to co-found Intel.

Thus, students do play a critical role at the interface of UBC. For students, UBC may lead to exposure to cutting edge technologies used in industry, developing employability skills, building professional networks and securing employment in industry. For firms, UBC can offer access to specialised skills in the commercialisation of its products and services and a pre-employment 'try-before-you-buy' look at students through sitting in dissertation committees, sponsoring of research projects and engaging in industry placement programmes. Despite these advantages, Stephan (2001) also critiques UBC in terms of poaching talented university staff to industry and away from training the next generation of innovators by consuming academics with industry-funded research and personal and university remuneration via contract research at the expense of student education. Therefore, she calls for a closer examination of the role of the student and education in UBC via industry placements.

Within the area of innovation and technology management education, the area of work-integrated learning (WIL) through industry placements has received increased attention in developing innovation skills through the uncertain and unstructured nature of real-world entrepreneurial environments (Kuratko, 2005). WIL is defined as "a structured strategy for integrating classroom studies with learning through productive work experiences in a field related to a student's academic or career goals" [Groenewald, 2004, p.17]. There are two main characteristics of WIL. First, it must involve partnership between the student, educational institution and employer, with specified responsibilities for each party (Abeysekera, 2006). Second, it must also involve reflection on learning from the experience (Katula and Threnhauser, 1999).

Despite these two common characteristics, there are various forms of WIL. The first form is cooperative education, characterised by a contractual arrangement between the university and firm which outlines the salary and work conditions, involves the hiring of 
students, alternates students between the firm and university and requires full-time university staff to assist students with their needs throughout the programme (Katula and Threnhauser, 1999). The second form of WIL is work-based learning (WBL) which offers flexibility both in entry and exit from the programme as well as scope and type of assessment, which poses problems in degree completion and integration between learning in the workplace and the curriculum (Abeysekera, 2006). The third form of WIL is workplace learning programme (WPL), which is based on the delivery of the course in the workplace. This is usually targeted to senior and middle managers. While it has the advantages of increasing student recruitment through reaching a professional market as well as being a source of new course material and research opportunities, it is expensive to administer as it requires additional staff travel and information and communications technology (ICT) services (Rose et al., 2001). The fourth type of WIL is community service performed through the faculty setting. This includes 'monitored service experiences' but may be seen as a form of cheap labour and unsuitable in an industry context (Katula and Threnhauser, 1999). The fifth type of WIL is the placement which involves a closely monitored work experience whereby the student has intentional learning goals and reflects actively on them. This provides students with opportunities for professional development and valuable work place exposure (Abeysekera, 2006; Katula and Threnhauser, 1999).

While the WIL literature has focused on various forms of WIL in different disciplines and its key benefits and characteristics, it has placed limited attention on how best to develop UBC. WIL has a long history in applied sciences in areas such engineering. In the engineering context, Shuurman et al. (2013) examined the benefits of cooperative education to students in terms of the likelihood of a job offer and a higher salary. The impact of WIL in developing entrepreneurial skills of venturing and technology self-efficacy in engineering students has also been established (Lucas et al., 2009). The WIL literature has generally assessed the benefits of WIL in terms of student satisfaction and skill development rather than UBC outcomes (Narayanan and Olk, 2010). For instance, in evaluating WBL, Freestone (2007) altered the course evaluation questionnaire to the work experience evaluation questionnaire and measured items such as good teaching, clear goals and standards, appropriate assessment, appropriate workload, generic skills and overall satisfaction. Others have examined benefits and challenges of various forms of WIL. Workplace learning has also been investigated in a social work context and the challenges of balancing full-time work and the achievement of learning competencies (Sobiechowska and Maisch, 2007). Abeysekera (2006) examined WIL in an accounting context and discussed the applicability of various forms of WIL to accounting education with placements deemed as the most appropriate due to the focus on learning outcomes and heavy immersion in the workplace. Additionally, other studies have examined how best to improve assessment and curriculum development (Kolb and Kolb, 2005). Generally, the WIL literature has investigated WIL predominantly from a teaching perspective rather than that of UBC, which can offer benefits in addition to education.

Therefore, the research question of this study in this paper is to examine 'how UBC can be developed through WIL placements, to not only strengthen WIL opportunities but to lead to other UBC outcomes. As illustrated in Figure 1, it will make an important contribution to the literature in uncovering how WIL-related UBC can foster wider UBC outcomes pertaining to research and commercialisation. 
Figure 1 At the interface: contribution of study towards research gap in WIL-related UBC research

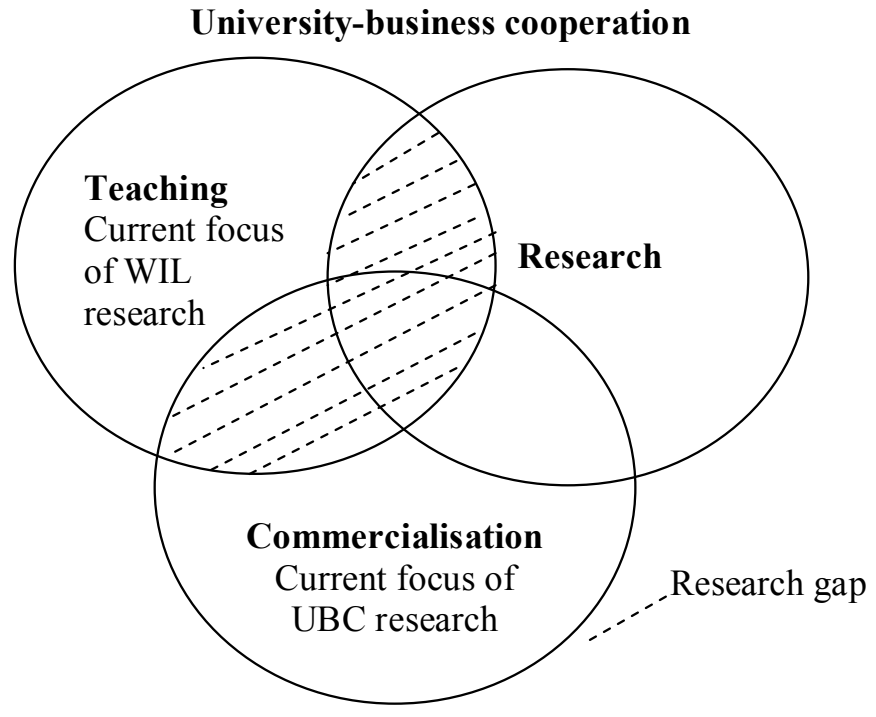

In so doing it will extend the WIL literature beyond its largely teaching focus to incorporate how it leads to wider UBC outcomes. It will also advance the UBC literature beyond its commercialisation emphasis to examine WIL related UBC. This marriage of the UBC and WIL literatures is important in effectively leveraging the potential of WIL in strengthening UBC as WIL becomes mainstream (McLennan and Keating, 2008; Orrell, 2004; Patrick et al., 2009).

The research will be based on a case-study of a university in Australia. Australia is seen as a suitable context given the prominence of WIL nationally (Freestone et al., 2007) with WIL in over $60 \%$ of Australian university courses (Reeders, 2000). WIL has gained popularity in Australia among employers in addressing skill shortages and recruitment issues and also among universities in improving the employability of their students which has implications for their reputations, retention rates and course demand statistics (McLennan and Keating, 2008; Orrell, 2004; Patrick et al., 2009). The university under investigation is seen as appropriate as it has been recognised for its leadership in WIL since 1996 (Cooper et al., 2011; Orrell, 2004). The paper will first provide a review of the UBC literature and the factors influencing the development of UBC. The method involving qualitative research and its results will then be discussed to reflect both student and industry perspectives on the role of WIL in UBC. The paper then concludes with implications for developing UBC via WIL to achieve broader UBC outcomes.

\section{Theoretical background}

UBC can be seen as a multi-dimensional, complex process requiring partnerships to be developed among multiple stakeholders at the organisational and individual levels (Perkmann et al., 2013; Wilson, 2012). In exploring the interaction among these multiple stakeholders, the UBC literature has identified pertinent factors that contribute towards the development of UBC outcomes including communication and coordination. 


\subsection{Role of multiple organisations in $U B C$}

At the organisational level, UBC stakeholders include the triple helix of university, business and government (Etzkowitz and Leydesdorff, 2000). University stakeholders comprise university administrators and academic staff (Siegel et al., 2003). Furthermore, university stakeholders can include staff members who come from different disciplines within the same university (Cardozo et al., 2002). The University of Minnesota, for example, recognises the importance of both engineering and management knowledge in its new product development course and brings together the two disciplines to create a project team for student work placements. Other university staffs includes WIL administrative employees that usually focus on providing information to firms about the WIL programme and ensuring that agreements are in place with industry hosts. Academic staffs are typically responsible for WIL curriculum issues, negotiating WIL projects with industry and providing academic supervision for WIL placements. WIL introduces the student as another potential university stakeholder. The increasing importance of students as a separate university stakeholder is a direct result of the increasing role of WIL in undergraduate and postgraduate courses (Papakonstantinou et al., 2013).

Business stakeholders refer to the managers within businesses and entrepreneurs in those firms engaged in UBC (Siegel et al., 2003). These businesses may host students for WIL placements. Government stakeholders include both federal and state governments that may provide funding for UBC, promote it within the industry and also offer WIL placements, for instance at various defence, environmental, water, transport and science-based public agencies. Although not always mentioned due to their less direct role, intermediaries make up the final key stakeholder group, which can influence university-business exchange (Wright et al., 2008). Intermediaries are commonly referred to as technology translators (Davenport et al., 1998), brokers (Hargadon and Sutton, 1997), bridgers (Bessant and Rush, 1995; McEvily and Zaheer, 1999), information intermediaries (Popp, 2000) and superstructure organisations (Lynn et al., 1996). In addition to improving connectedness and bridging ties within the innovation system, intermediaries may also 'create new possibilities and dynamism within the system' [Howell, (2006), p.726]. Some examples include technology transfer offices, incubators and science parks.

\subsection{Role of the individual}

In additional to the organisational level, UBC also occurs on the individual level. The role of the individual has long been prevalent in the management literature, with a predominant focus on individuals in firms and various managerial roles such a liaison, monitor and spokesperson (Minzberg, 1973). Similarly, marketing studies have examined roles at the individual level when researching sales people with concepts such a role ambiguity, clarity and conflict (Chonko et al., 1986; Ford et al., 1975; Netemeyer et al., 1996; Rizzo et al., 1970; Singh and Rhoads, 1991). More recently, network theorists have also investigated the role of the individual in networks, particularly in a private sector context. For instance, Heikkinen et al. (2007) suggest roles appropriate for specifically managing in networks, including webber (initiates connections and influences network development), producer (conducts concrete work), facilitator (offers venues, resources and possibilities), gatekeeper (possesses power to decide and shape directions), entrant (interferes with network development), aspirant (aims to become part of the network), 
instigator (causes change by influencing decisions), planner (influences outcomes of the process), compromiser (ready to give up own goals), advocate (passes on positive information), auxiliary (incrementally involved) and accessory provider (remote role, not directly involved). However, like most role theorists, little attempt has been made to link role theory to outcomes within networks.

In addition to firm individuals, past studies have also examined government individuals. For instance, Turpin and Deville (1995) conducted a study in a public research institute, the Australian Commonwealth Scientific and Industrial Research Organisation (CSIRO) and discussed the shift in the role of scientists from research scientists to more commercial roles as research managers and commercial managers. When working in network contexts, past researchers have also identified the need for a boundary rider role (Turpin et al., 1996). Another study based on the government-led cooperative research centre (CRC) programme in Australia focused on the challenges for government researchers in reconciling the demands between reward systems in academia focused on 'discovery' while confronted with the need to focus on 'application' when collaborating with industry (Garrett-Jones et al., 2005).

Similar to studies examining roles within government, studies examining the role of individuals in university are generally limited to staff and largely ignore the role of students (Siegel et al., 2003). For instance, in D'Este and Patel's (2007) study of 1,528 academic staff in the UK, they found that the individual characteristics of academic researchers have a stronger influence on the type and frequency of interactions with industry, compared to the characteristics of their faculties or universities. Academics with a history of past interactions, their academic status such as 'professor' and the younger academic are involved more frequently and in a greater variety of collaborations with industry. Results from others (e.g., Perkmann et al., 2013) add to the list of individual characteristics that can influence UBC. Male academics, for example, are significantly more likely to collaborate with business. The social skills of the individual can be used to resolve and manage barriers to successful UBC such as perceived differences between universities and firms (Bjerregaard, 2010) and also to create 'instant rapport' that is necessary for engagement (Plewa et al., 2013). However, the focus of existing UBC studies has been on the university academic researcher and not on the student (Stephan, 2001).

Conversely, while the WIL literature does offer student perspectives, the focus is generally on teaching outcomes (such as curriculum, learning outcomes, student satisfaction and assessment issues) rather than UBC (Freestone et al., 2007; Lucas et al., 2009; Sobiechowska and Maisch, 2007). Although some WIL studies anecdotally recognise that WIL can lead to other forms of UBC such as research collaboration (Patrick et al., 2009), there is little empirical evidence on how WIL can lead to the development of UBC from the perspective of individual stakeholders including university students and individuals in firms and government, thereby reflecting the need for further research in this area.

\subsection{Communication}

Communication is also essential in UBC (Plewa et al., 2013). Communication, involves the movement of information between parties via one or more channels. For communication to be efficient, it must be transparent, credible, codified in a form that each intended party will understand, conform to any confidentiality requirements and be 
cost effective (Moenaert et al., 2000). Plewa et al. (2013) examine communication at various phases in UBC including the establishment phase (which involves discussion and agreement on the scope of the collaborative work); the engagement phase (focusing on working together among partners); and the advancement phase (which revolves around creating value beyond initial scope of work). Communication in the establishment phase usually involves one to one, frequent and face-face discussions focused on understanding each party's strengths, requirements and expectations and in establishing project parameters. During the engagement phase, the nature of the communication is focused on 'building trust' and familiarisation with the work habits and patterns of the different stakeholders. The nature of the communication shifts again as the project moves towards the engagement and advancement phase. During these stages the nature of the communication becomes more frequent, open and 'professional' as the objectives of the collaboration shift towards the delivery of outcomes and exploring opportunities for ongoing engagement.

In a WIL context, Narayanan and Olk (2010) argue that communication can range from arm's length where there is sparse communication between the university and the firm to embed characterised by high levels of communication. Additionally, Rounce et al. (2007) found that language was a highly contentious issue in WIL communication between firms and universities as terminology was confusing and there was little shared understanding.

\subsection{Coordination}

Coordination is another important factor in developing UBC. Coordination is about cooperation between different stakeholders and it is the cooperation in UBC that enables companies to address and manage the challenging cross-disciplinary nature of the innovation process (Morandi, 2013). Coordination is defined as the level to which the partners collaborate effectively in achieving shared outcomes (Mohr et al., 1996; van de Ven, 1976). The term refers to the overseeing and management of every stage of the interaction between a university and a firm, from the initial engagement to the delivery of the outcomes and termination of the collaboration (Morandi, 2013). Rampersad et al. (2010) adds that coordination in a UBC context requires objectives, a moderate degree of formality and a single figure of authority that manages the interaction. However, they maintain that coordination should not be excessively rigid so that innovation is hindered to the point that stakeholders spend excessive time in reporting at the expense of innovating.

In the WIL context, Narayanan and Olk (2010) explain that coordination pertains to the appointment of both university and business supervisors who mentor and provide feedback to students during the internship. More broadly, Rounce et al. (2007) argued that it also involves planning and clarifying purpose and outcomes in the WIL context.

\subsection{UBC outcomes}

The UBC literature has focused on outcomes pertaining to commercialisation and research rather than teaching and WIL specifically. The primary commercialisation measure is patents. However, this measure has been widely criticised as it fails to capture other forms of innovation such as service innovation that may not be patentable and even some new products associated with small firms who may not deem patenting as the most 
feasible or appropriate commercialisation strategy (Acs et al., 2002; von Hippel, 2009). As a more holistic indicator of commercialisation outcomes, Harmon et al. (1997) argue that the number of new products and services is more suitable for output stemming from UBC.

Other UBC outcome measures exist beyond commercialisation. First, research outcome measures from the UBC literature include publications, completion of research theses, research income and international linkages (Barnes et al., 2002; Groot and Garcia-Valderrama, 2006; Perkmann et al., 2011). Second, the hiring of skilled students is a key outcome of WIL for both firms and students (Bishop et al., 2011; Knemeyer and Murphy, 2001; Narayanan and Olk, 2010). Additionally, the UBC literature has also adopted relational measures to assess UBC outcomes such as intention to renew the cooperation (Plewa and Quester, 2007). Renewal intent reflects behavioural intention to continue commitment and to maintain engagement with the programme (Daniel et al., 2002).

\section{Method}

In order to integrate the UBC and WIL literatures, this study examines factors contributing towards the development of UBC in a WIL context. This study was undertaken at a medium-sized university in Australia from September 2012 to February 2013. WIL has enjoyed increased prominence in Australia and therefore, the Australian context is significant for this research (Freestone et al., 2007). The study was based on a case study of a WIL placement programme at the university involving science and engineering students (26 engineering students in their third, penultimate year of study as well as eight information technologies and six business and technology students in their final year of study). The 20-week full-time placement was a core component of the degree and focused on an innovative industry project, for instance the development or commercialisation of a new technology, product or service. A case study approach was selected as it provides the benefit of detailed capture of reality (Galliers, 1990). A university can be seen as an innovation ecosystem as it consists of a live set of actors that also engage with the broader regional and national innovation ecosystems through the UBC interface (Fukuda and Watanabe, 2008; Innovate America, 2004). Jackson (2013) explains that an innovation ecosystem refers to complex relationships between actors and entities, with a goal of technology development and innovation. She argues that the ecosystem comprises actors such as students, faculty, researchers and entities including schools of engineering, business and industry-engagement units. WIL is an instrumental component in building broader UBC through integration with the technology transfer office and entrepreneurial initiatives in the university. The university chosen as the context of this research is a recognised leader in WIL which is included in all undergraduate degrees (Cooper et al., 2011). As illustrated in Figure 2, WIL students at the university are associated with the technology transfer office, the incubation of new firms and contract R\&D centres in the university, the university commercialisation software, come from a variety of education programmes in the university and liaise with a number of host firms and government agencies. 
Figure 2 University innovation ecosystem at the UBC interface and the role of WIL

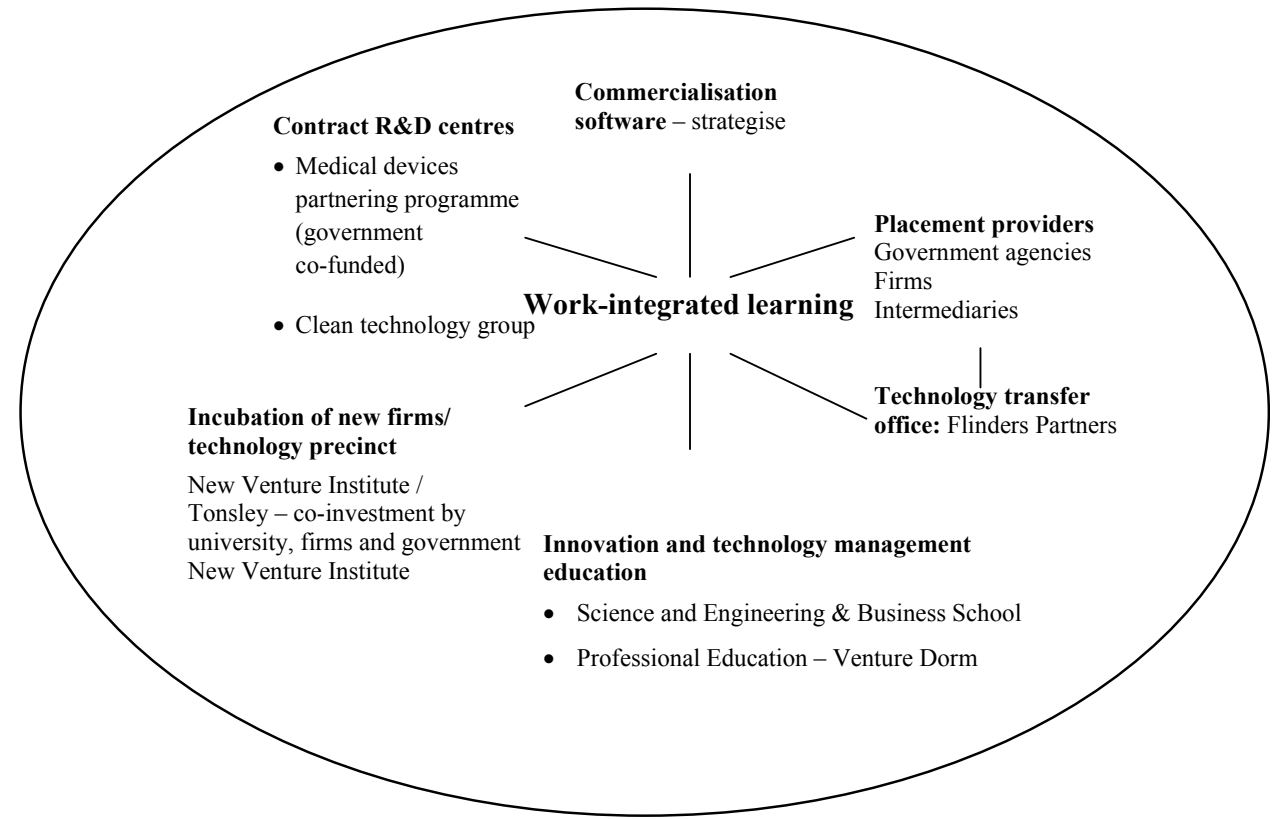

Research examining the role of students and WIL at the interface from a UBC perspective is limited (Astebro et al., 2011; Stephan, 2001). Therefore, the qualitative approach was appropriate in this context for exploring emerging themes of multi-faceted and complex processes (Cassell and Symon, 1994; Smith and Fischbacher, 2005). The research design employed included semi-structured interviews with industry supervisors from firms and government as well as students from university, thereby reflecting the triple helix of organisations. Respondents were required to discuss the role of WIL in UBC. Interviews generally lasted one hour and were tape recorded to promote rapport with interviewees (Blaxter et al., 2001) and transcribed. This interview data was triangulated with data from reflective $\log$ books by students and reports by student-industry supervisor dyads which were provided on placement completion. All WIL industry supervisors and students were invited to contribute to the research and 80 invitees from 40 employer-student dyads agreed to participate. Industry supervisors were managers from various types of organisations across the private and public sectors. Twenty-six industry supervisors were from the ICT sector (industry supervisors, students 1-26), five were from the medical device sector (industry supervisors, students 27-31), four pertained to mechanical engineering (industry supervisors, students 32-35) and five were from the clean technology sector (industry supervisors, students 36-40).

Guided by UBC themes as illustrated in Table 1, qualitative data analysis was then conducted, with data from interview transcripts, supervisor evaluation reports and student logbooks and reports that were all placed into NVivo. 
Table 1 Key themes guiding analysis

\begin{tabular}{|c|c|}
\hline Key themes & Literature sources \\
\hline Role of the organisation & $\begin{array}{l}\text { Cardozo et al. (2002), Etzkowitz and Leydesdorff (2000), } \\
\text { Papakonstantinou et al. (2013) and Siegel et al. (2003) }\end{array}$ \\
\hline Role of the individual & $\begin{array}{c}\text { Ankrah et al. (2013) Bjerregaard (2010), D’Este and Patel } \\
\text { (2007), Heikkinen et al. (2007), Garrett-Jones et al. (2005), } \\
\text { Perkmann et al. (2013), Siegel et al. (2003), Turpin et al. } \\
\text { (1996) and Turpin and Deville (1995) }\end{array}$ \\
\hline Communication & $\begin{array}{l}\text { Moenaert et al. (2000), Narayanan and Olk (2010), Plewa } \\
\text { et al. (2013), Rampersad et al. (2010) and Rounce et al. } \\
\text { (2007) }\end{array}$ \\
\hline Coordination & $\begin{array}{l}\text { Mohr et al. (1996), Morandi (2013), Narayanan and Olk } \\
\text { (2010), Rampersad et al. (2010), Rounce et al. (2007) and } \\
\text { van de Ven (1976) }\end{array}$ \\
\hline UBC outcomes & $\begin{array}{c}\text { Barnes et al. (2002), Bishop et al. (2011), Groot and } \\
\text { García-Valderrama (2006), Harmon et al. (1997), } \\
\text { Knemeyer and Murphy (2001), Perkmann et al. (2011) and } \\
\text { Plewa and Quester (2007) }\end{array}$ \\
\hline
\end{tabular}

Employing thematic analysis, codes were applied as data patterns emerged and then data was assembled under each code (Carson et al., 2001; Miles and Huberman, 1994). Following Yin (1994) construct validity was facilitated via the triangulation of information from various sources including employers and students as well as different industries. These multiple perspectives reduce the likelihood of bias (Choudhrie et al., 2003; Patton, 1990).

\section{Results}

The results examine key factors for developing UBC through WIL. It revealed the instrumental role of WIL at the UBC interface in contributing to broader UBC outcomes. Figure 3 reflects the conceptual framework which emerged from the literature and the qualitative data about how WIL can lead to the development of UBC. It will be discussed further in this section.

UBC through WIL is a dynamic, complex set of interactions, an interweaving dance between the organisational and individual levels. Therefore, results reflected the important role of organisations as well as individuals involved in communication and coordination processes to lead to UBC outcomes. 
Figure 3 Framework for developing UBC via WIL

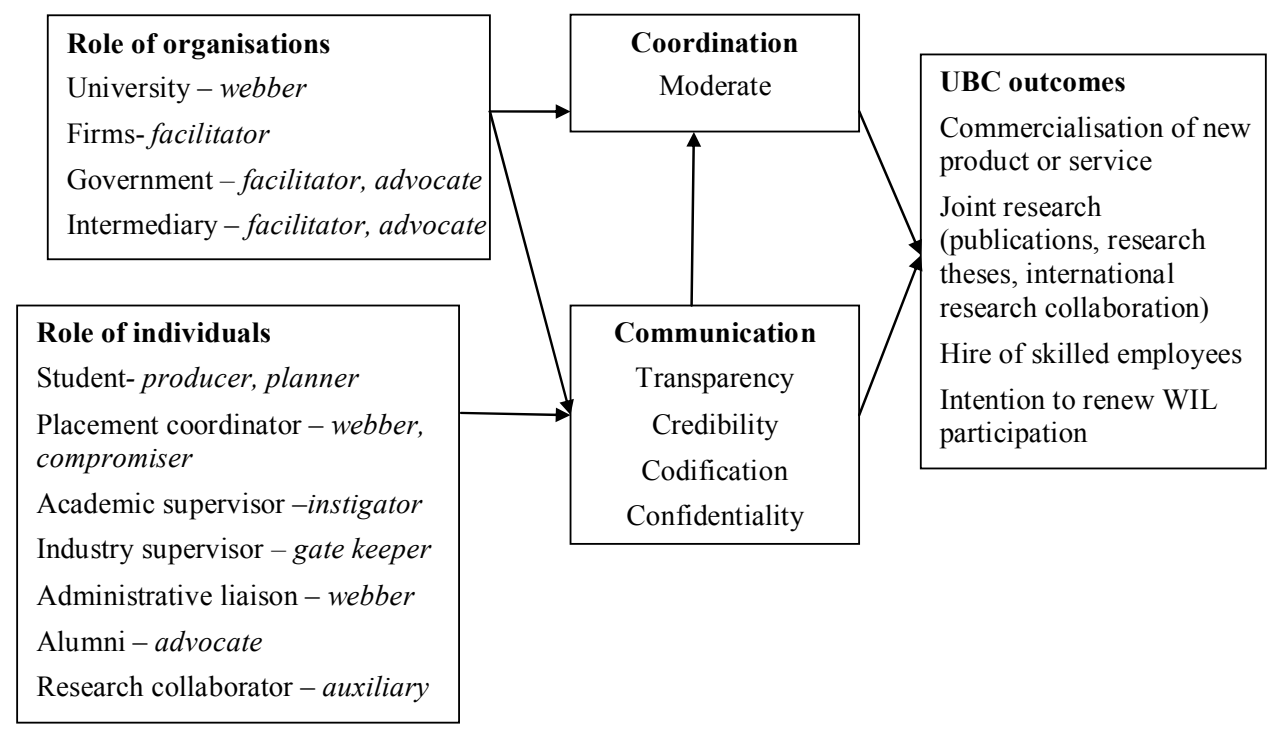

\subsection{Role of organisations}

The results reflected the role of the university as a webber in the process as it initiated connections and influenced the development of the network. The university had a database of contacts and had brochures in place about the placement programme which articulated the capabilities of students with information on their associated degrees, skills, typical projects that they can work on for firms, such as business plans, e-commerce websites, mobile iPad applications, engineering products and services and R\&D projects. The university also had a process in place which prompted firms to complete an online industry interest form outlining the project and any skills and capability requirements. These projects were then promoted via an online system to students who applied on a competitive basis. Once firms selected students, the university had WIL policies requiring agreements and work plans be signed between each organisation and academic supervisors were allocated to each student. As the placement unfolded, the university required that students submit logbooks and interim reports as part of the official assessment and at the end of the placement, final student reports and the completion of evaluation reports by both students and firms were also necessary. A university expo was also held at the end of the placement period involving student presentations and invitation of industry supervisors and academics involved in the placement process as a means of recognising work accomplished and cementing future collaboration. 
"The placement process is well structured with the project student matching process appearing to work very well. We are keen to stay involved with it in the future." (Industry supervisor 4)

The placement provider, either a firm or a government agency, acted as a facilitator as they offered a venue, resources and possibilities of placement projects. For instance they were required to ensure that students were given occupational health and safety training that would usually be given to employees; had a desk, computer or relevant resources; was allocated a supervisor and was given fortnightly feedback and a clear work plan from the start of the project, thereby positively influencing coordination.

Government agencies as well as intermediaries served as advocates of the placement programme. Given that they were influential nodes, they had access to large pools of relevant organisations and used their newsletters to showcase relevant case studies to demonstrate the value of the WIL placement programme to its member organisations. Some government agencies included Business Enterprise Centres while other intermediaries included key industry associations such as the Defence Teaming Centre (DTC), Business SA, Australian Industry Group, Technology Industry Association (TIA), Engineers Australia and the Australian Computer Society.

\subsection{Role of individuals}

Qualitative data confirmed the UBC literature about the important role of individuals (Ankrah et al., 2013; Bjerregaard, 2010). Although the university had polices and processes established to foster connections with industry, the placement coordinator and administrative liaison also served a key webbers at the individual level to initiate new relationships with prospective hosts and to influence the development of the network through ongoing activities to strengthen existing relationships, thereby positively influencing communication. Since placement projects were determined by industry, the placement coordinator also acted as a compromiser, for instance, in being flexible to organisational recruitment deadlines and preferences of commencement dates for placements. The academic supervisor was portrayed as an instigator during the placement given his/her influence in decisions. This supervisor visited the student at the placement to ensure that the student was integrated into activities of the firm, was given relevant training and resources and was also responsible for marking the students' assignments. These visits provided face-to-face time to build rapport between organisations, to understand each other's interests and to identify future opportunities for collaboration, leading to strengthened communication. The industry supervisor can be seen as a gate keeper as he/she had the power to decide the direction of the project. The student role was seen as a planner and producer as they developed project specifications and then carried out the work.

Findings reflected the significance of alumni as advocates in catalyzing further UBC (Siegel, et al., 2003). In addition to offering several placements to students, the alumnus, industry supervisor 1, was engaged in a number of UBC activities including judging of presentations, guest lecturing and promotion of industry placement programme.

"Eight years ago I did a placement at [a firm] where I am now employed as the Software Development Manager. My placement project now represents the main product and the largest source of income for the firm. We have had eight placement students over the past eight years and have hired five of them." (Industry supervisor 1) 
In addition to alumni, findings also illustrated the role of other university stakeholders in UBC including employees and research collaborators as auxiliaries who become incrementally involved in the placement programme as they were first involved in research activities, thereby confirming the UBC literature (Siegel et al., 2003).

"I got a privilege to stay in Adelaide in the early 90's for more than three years working as a research officer at the [university], Department of Civil and Environmental Engineering... Since then we have performed joint research work on fluid transients. There is an opportunity for future placements too (from 2014 on -year 2013 is booked)." (Industry supervisor 32)

\subsection{Communication}

The qualitative data confirmed the importance of each of the dimensions of communication efficiency including transparency, credibility, codification, secrecy and costs stemming from the UBC literature (Moenaert et al., 2000).

On the organisation level, transparency was ensured as information on the placement programme was provided via brochures and websites. Additionally, the university required that a work plan be signed by three parties, the industry supervisor, student and university supervisor to ensure that the scope of the project was transparent. On the individual level, interviewees also emphasised the importance of transparency in communication via both formal and informal channels:

"One very positive point was our involvement in all other information sharing related projects including formal and informal meetings, small group and large group meetings as well. This is probably the number one important factor in the organisation that helped us gain a greater understanding of the problems." (Industry supervisor 8)

In addition to offering transparent information, credibility was also seen as important by firms and students. Participants felt that credibility was important in terms of identifiable sources of information:

"Teleconferencing with people from various locations is a challenge. ... Knowing exactly whom one is talking to without specifying names can be a problem. This is further exacerbated when two participants have the same name, which occurred once, and caused plenty of confusion for me." (Student 2)

Codification emerged as an issue particularly in the use of commonly understood language and terminology away from technical academic jargon towards business focussed language:

"Written communication was also improved with the use of the main business plan document to develop business language." (Student 1)

The qualitative data confirmed sensitivity to communication cost issues. The agreement signed between organisations required meetings between industry supervisors and students to occur fortnightly while the university required academic supervisors to visit students at least twice during the placement and to maintain weekly contact. Students 1 and 6 expressed a preference for more frequent meetings while their supervisors had other external or overseas meeting obligations, thereby highlighting the issue of communication costs associated with the frequency, duration and mode of 
communication. Student 7 pointed out the scheduling of meetings with his supervisor as a difficulty in his placement.

"One notable occurrence was when [industry supervisor 7] was away for
approximately one month. A meeting was rescheduled nearly a week from
when it was originally meant to occur." (Student 7)

Confidentiality also emerged as a significant issue in communication efficiency in UBC involving WIL. A confidentiality clause was included in the agreement and a guest lecture was arranged with a patent attorney to sensitise students to confidentiality issues prior to commencing their placements. Firms noted that students were well prepared for such confidentiality concerns:

"[Student 8] is aware of and sensitive to the privacy concerns that bind [placement organisation 8]. He has not acted in any way that undermines the commercial interests of [the firm]." (Industry supervisor 8)

\title{
4.4 Coordination
}

The results confirmed the findings in the UBC literature that coordination is important for UBC (Rampersad et al., 2010). Coordination involved several activities for each placement from initiation where the firm outlined a project; planning whereby a work plan was completed and signed by the industry supervisor, student and university supervisor; execution of the project by the student; monitoring by the industry and university supervisors; and closing through reflection and evaluation by student and industry supervisor. Industry supervisors particularly emphasised the importance of regular planning activities.

"[The student] and I sat down and planned each week and then [the student] worked the plan." (Industry supervisor 2)

Students also confirmed the need for moderate coordination that is not too rigid (Rampersad et al., 2010). This allowed them to demonstrate initiative whereby they can offer solutions rather than being overly directed through each step.

\begin{abstract}
"In general, because [my supervisor] spends most of his time interstate, I received notably less supervision than what I am used to. This proved to be a blessing, however, because it allowed me to demonstrate initiative. Whenever I was unsure of what to do, rather than seeking help from my supervisor, as perhaps I would previously be inclined to do, I tried to think about what the answer to my question would be from the perspective of my supervisor. Most often, I was able to direct myself to exactly what was required without any supervision. Even when I did not immediately hit the mark with what was required, the tangential work undertaken would still prove valuable at some point or another." (Student 2)
\end{abstract}

\subsection{Outcomes}

Building on the mapping by Harmon et al. (1997) by technologies transferred, organisational type and size, this mapping is extended to analyse the outcomes of the collaboration including commercialisation of new products and services, joint research leading to publications, research honours projects, research income and international research collaboration, recruitment of skilled students and intention to renew WIL participation as detailed in Table 2 and further discussed in this section. 
Table 2 Mapping UBC through WIL by type of technology and organisation

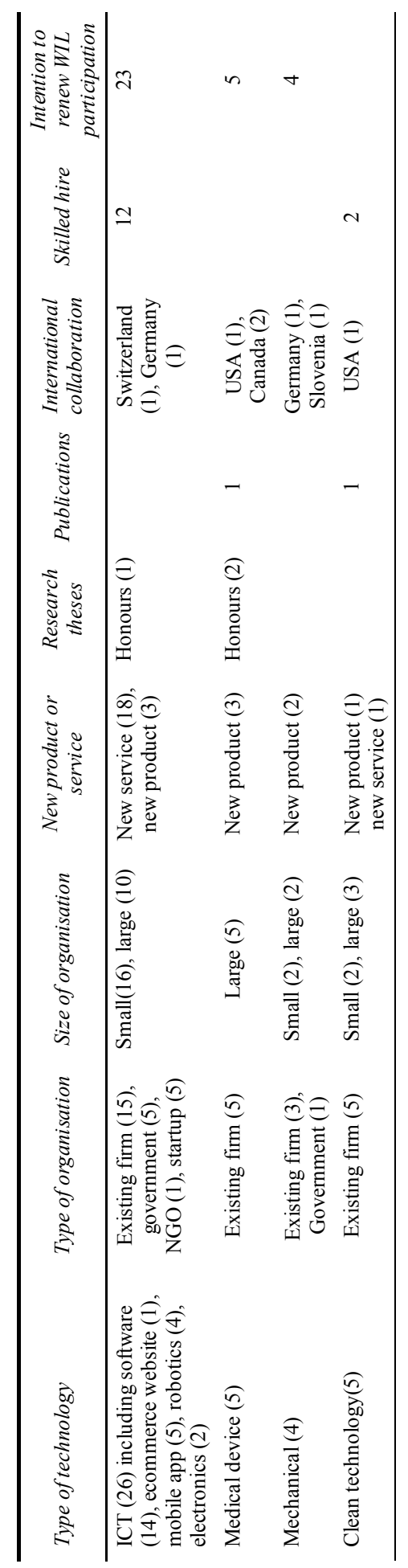




\subsection{Commercialisation of new products and services}

Qualitative data confirmed the contribution of WIL students to the commercialisation of new products and services.

"[Student 5] developed the design for [name of innovation] mobile application. [Student 5] was very adaptive (agile) and iteratively improved the application. What started as a simple app for an invention health check has finished as a product to support an innovation community." (Industry supervisor 5)

"His intellectual scope is impressive, and his ability to turn ideas into working prototypes is highly valued." (Industry supervisor 10)

"[My organisation] is a strong supporter of the industry placement program. The program enables students to gain valuable experience into their chosen profession, to build stronger networks with university and business, and to ensure that students enter the workplace with the required skills. For our business it is an ideal way of evaluating future employees and assists in injecting new ideas into our operations and services provided. In our experience, it has opened our business to further commercial markets and assisted our ability to provide modern services to our customers." (Industry supervisor 1)

"[Student 2] designed and built [a new service]. These are new offerings leveraging emerging technologies and requiring innovative and creative thinking to execute... We will release the offerings [student 2] worked on in the week following the completion of his placement." (Industry supervisor 2)

"Student 2 reflected on the same project: my work on the project was innovative in the sense that it added an additional feature that has contributed to creating a unique set of services." (Student 2)

\subsection{Joint research}

As indicated in Table 1, WIL placements lead to further joint research via research honours projects, academic publications and research funding.
"His placement focused on developing a database system to monitor water pollution compliance with grey water legislation to reduce pollution from recreational and commercial vessels. He is currently still employed by [our organisation]. Additionally, he has collaborated with the university in publishing about his work at [our organisation] and had the opportunity to present this work at a high-ranking international conference on information systems in December 2012 in Orlando Florida as well as to relevant government agencies overseas in the USA (Fradley et al., 2012).” (Industry supervisor 10)

WIL also led to international collaboration as it included inter-state and international placements. In 2012, students have been placed in Sydney and Melbourne and internationally in the US, Canada, Switzerland, Germany and Slovenia. A Canadian organisation discussed the key role of the student and WIL in ongoing international research collaboration:

"[The students] have brought immense creativity and enthusiasm to various research projects at [our organisation]. Their contributions have directly resulted in the publication of scientific articles and the advancement of several access technologies." (Industry supervisor 29) 
Furthermore, discussions about research funding opportunities also arose as a result of WIL related UBC.

\begin{abstract}
"I would be glad to strengthen the bounds between our academic institutions... there exist numerous other funding opportunities via DAAD (see www.daad.de). Funding can be obtained for semesters (i.e., course work), projects or theses abroad. I would be grateful if you could make your students aware of these opportunities." (Industry supervisor 33)
\end{abstract}

\title{
4.8 Hire of skilled employees
}

As indicated in Table 1, several firms hired students following their placement (approximately 35\% of all students were hired by their placement organisation). This number should be interpreted in light of availability and other study commitments of the students. Engineering students are generally not available for hire following their placement as they return to university to complete their final honours year in year 4. Given that 26 out of 40 students were from engineering and therefore unavailable immediately for further employment, the results suggest that the majority of students who completed their placement in their final year (and therefore available for employment following their placement) were hired.

"[Student 6] is very technically capable and has a very good appreciation of the commercial world. I aim to employ him at the end of his placement." (Industry supervisor 6)

"We are very confident in [student's] ability and are very happy to employ [student 1] in the role of Software Development Engineer at the completion of his studies." (Industry supervisor 1)

\subsection{Intention to renew WIL participation}

As indicated in Table 1, qualitative data confirmed intention to renew WIL participation as a key outcome (Plewa and Quester, 2007).

"We look forward to offering placements to further this project and start others." (Industry supervisor 10)

"We would be delighted to continue to be involved in the industry placement scheme and to deepen our connection with the university." (Industry supervisor 2)

"[My firm] would be interested to be involved in further placements with other students." (Industry supervisor 7)

"We would be happy to participate in the industry placement scheme in future years and are open to further collaboration." (Industry supervisor 28)

"[My firm $]$ is definitely interested in supporting this program in the future and is open to any suggestion of further collaboration with the university." (Industry supervisor 1) 


\section{Discussion}

Within the university environment, the areas of teaching and research have been recognised as key areas with clear metrics of performance measurement, while the area of industry engagement is less clear. For instance, teaching has been assessed via student evaluations and research has been judged via a number of metrics such as publications, patents, grant income and citations. There are usually top management staff such as deputy vice chancellors and deans associated with teaching and research and reward systems within the university environment such as performance evaluations and promotions are generally framed within teaching and research metrics. While there is sometimes, top management staff associated with UBC (such as deputy vice chancellors for community engagement or associate deans for industry outreach); there remains less clear metrics in the university sector around $\mathrm{UBC}$ and little integration with related process around teaching and research. This is a problem as it can lead to UBC being undervalued with the level of work and time involved being underestimated. Moreover, lack of clarity can mean that universities do not adequately leverage UBC opportunities which can add relevance and impact for their research and teaching activities. This research was important in showing how engagement through UBC is a core component or even an umbrella for teaching and research activities and how WIL is vital glue between these activities and a catalyst for further UBC (Figure 1). It helps in translating the UBC process into tangible factors which can be managed. In particular, the results extended current understanding on how WIL can be managed through a focus on the role of organisations and individuals and their impact on communication and coordination in bringing about UBC outcomes including those pertaining to research and teaching.

The study also provided deeper understanding into the complexity and dynamics of roles within the UBC process. In contrast to past role theories that examine roles mainly from the individual level, results reflected the identification of roles both at the individual as well as organisational levels. For instance, webber roles in initiating and developing connections occurred both at the organisational level as the university had policies, processes and databases in place that supported the development of relationships. However, particular individuals such as the placement coordinator and administrative liaison also conducted personal outreach activities beyond usual university processes and systems. In addition extending past literature which has not attempted to link role theories to outcomes, this study integrated the concept of roles within a framework to link it to UBC outcomes, thereby contributing to theory development.

Indeed, the research clarifies our understanding of engagement through UBC by linking it to tangible drivers and outcomes within the context of research and teaching outcomes. Past literature has viewed engagement such as UBC as a precursor or alternatively an outcome of interaction or even an iterative process with various cognitive, emotional and behavioural dimensions (Brodie et al., 2011). Engagement has been referred to as a psychological state based on interactive experiences with an actor (Brodie et al., 2011). It has featured in a variety of disciplines such as sociology, psychology, politics and more recently in management and marketing, with calls for more research on the concept of engagement between various stakeholders such as university and industry (Brodie et al., 2011). The UBC literature has predominantly focused on university staff and industry around commercialisation. This study introduces WIL as an important component of UBC as teaching and the student have largely been ignored in past literature (Harryson et al., 2007). 
Hence, the results shed light by breaking down an iterative, dynamic UBC engagement process into key factors and outcome metrics so that he can assist in the management of UBC through WIL. The results reiterated how the triple helix of organisations including university, business and government are important in the WIL process. It also drilled deeper into the important role of individuals within organisations including students and industry supervisors who may be alumni or affiliates of universities. It uncovered key processes of communication and how to foster transparency, credibility, codification and met confidentiality requirements within UBC; as well as steps involved in moderate coordination. The results then showed the relevance of metrics pertaining to research (joint research and the commercialisation of products and services), teaching (hiring of graduates) and strengthened UBC (intention to renew WIL participation).

\section{Conclusions}

The purpose of this study was to examine how UBC can be developed through WIL placements, to not only strengthen WIL opportunities but to lead to other UBC outcomes. Unlike existing WIL studies that have a predominant teaching focus (Freestone et al., 2007; Lucas et al., 2009; Narayanan and Olk, 2010), the study contributed a UBC focus of WIL by examining how WIL partnerships can be developed to not only substantiate WIL efforts but to lead to broader UBC outcomes including research and commercialisation. Furthermore, unlike UBC studies that have under-recognised the role of education and students in UBC, the study extends the UBC literature beyond its commercialisation focus to incorporate WIL-related UBC given calls for greater research on a student focus of UBC (Astebro et al., 2011; Stephan, 2001). Moreover, the study advances role theory within the network literature by integrating roles within a framework and linking them to UBC outcomes. Adopting a qualitative approach including data from both students and industry supervisors from firms and government, it contributes a framework for UBC through WIL incorporating the important role of the organisation, individual, communication and coordination in achieving valuable UBC outcomes around the commercialisation of new products and services; joint research resulting in publications, research students, research income, international research collaboration; the hiring of skills students; and the intention to renew participation by industry in the WIL programme. Therefore, this study is an important marriage of the UBC and WIL literatures to cross-fertilise and extend their coverage by contributing the important but often overlooked area of WIL-related UBC.

The study provides important managerial implications for triple helix players engaged in UBC. For universities involved in WIL programmes, given that results emphasised the important role of individuals such as alumni and past employers in WIL programmes and broader UBC stemming from WIL, universities should actively engage with such individuals with their WIL programme. Alumni could be invited to sponsor WIL projects. Towards the completion of the placement alumni can be asked whether they are interested in other forms of UBC such as participation in advisory curriculum boards, mentorship of students, guest lecturing, research sponsorship and serving as key advocates of the WIL programme in industry outreach activities. Additionally, reflecting the results about communication, universities should ensure that information about the placement programme is transparent and accessible on brochures and websites; credible 
via official means and through key reputable nodes including industry associations; in language that is understandable to all parties; and that caters for confidentiality considerations by host organisation. Resonating with results from the study, coordination should not be overly excessive which may be distracting from the placement project.

The study also offers valuable insights to businesses seeking to engage with universities. Given that results revealed the important role of individuals such as alumni, firms should encourage their employees to maintain relationships with their Alma Maters and to serve as industry supervisors for projects as part of their community engagement/corporate social responsibility activities. Additionally, results emphasised the importance of communication within WIL projects. Firms should ensure transparency in communication via both formal and informal meetings. The study also indicated that firms should have appropriate coordination processes for participating in WIL. A supervisor from the firm should be allocated to oversee the placement student. The firm should outline the scope of the project that they will like the placement student to undertake and the supervisor should periodically monitor completion of the agreed tasks during the course of the placement.

In addition to implications for serving as hosts similar to businesses, additional recommendations are also offered to government agencies and intermediaries. Results revealed the importance of credible communication through partnership with influential nodes with a large network of partners. Therefore, government agencies with innovation mandates for linking business with the research sector should assist in promoting placement programmes and success case studies in newsletters and websites. Local government agencies with responsibilities for economic development may be interested in promoting outcomes such as hiring of placement students reflecting job creation and the commercialisation of products and services illustrating innovation within a region.

Despite its important implications, the study does have limitations and paves the way for future research. First, it included a single case study of a university and thus future research in other universities and disciplines can increase generalisability of results. For instance, business schools have an increasing interest in WIL in boosting the relevance of their programmes and the employability of their students (Abeysekera, 2006). Second, a quantitative study can be used to advance and test the conceptual framework proposed in this research. The quantitative results may be used to evaluate the significance of various roles and can help inform the development of staffing profiles and function specifications such as administrative liaison staff, placement coordinators and academic supervisors. Quite often in the university system, engagement roles and functions are not adequately defined and recognised given the predominant focus on teaching and research functions. Therefore, by examining the significance of various roles on UBC outcomes, such research can offer evidence-based recommendations to inform job design, work load allocation and performance evaluation for academic and professional profiles in adequately understanding UBC roles. Third, a longitudinal study can also help in examining the impact of WIL on furthering UBC through time. This helps in understanding the evolution of UBC which can provide implications for the effective management as relationships mature. Indeed, this study is an important first step in understanding the instrumental role of WIL and the student at the UBC interface. 


\section{References}

Abeysekera, I. (2006) 'Issues relating to designing a work-integrated learning program in an undergraduate accounting degree program and its implications for the curriculum', Asia-Pacific Journal of Cooperative Education, Vol. 7, No. 1, pp.7-15.

Acs, Z.J., Anselin, L. and Varga, A. (2002) 'Patents and innovation counts as measures of regional production of new knowledge', Research Policy, Vol. 31, No. 7, pp.1069-1085.

Ankrah, S.N., Burgess, T.F., Grimshaw, P. and Shaw, N.E. (2013) 'Asking both university and industry actors about their engagement in knowledge transfer: what single-group studies of motives omit', Technovation, Vol. 33, Nos. 2-3, pp.50-65.

Astebro, T., Bazzazian, N. and Braguinsky, S. (2011) 'Startups by recent university graduates and their faculty: implications for university entrepreneurship policy', Research Policy, Vol. 41, No. 4, pp.663-677.

Barnes, T., Pashby, I. and Gibbons, A. (2002) 'Effective university-industry interaction: a multi-case evaluation of collaborative R\&D projects', European Management Journal, Vol. 20, No. 3, pp.272-285.

Bessant, J. and Rush, H. (1995) 'Building bridges for innovation: the role of consultants in technology transfer', Research Policy, Vol. 24, No. 1, pp.97-114.

Bishop, K., D’Este, P. and Neely, A. (2011) 'Gaining from interactions with universities: multiple methods for nurturing absorptive capacity’, Research Policy, Vol. 40, No. 1, pp.30-40.

Bjerregaard, T. (2010) 'Industry and academia in convergence: micro-institutional dimensions of R\&D collaboration', Technovation, Vol. 30, No. 2, pp.100-108.

Blaxter, L., Hughes, C. and Tight, M. (2001) How to Research, Open University Press, Buckingham and Philadelphia.

Brodie, R.J., Hollebeek, L.D., Juric, B. and Ilic, A. (2011) 'Customer engagement: conceptual domain, fundamental propositions, and implications for research', Journal of Service Research, Vol. 14, No. 3, pp.252-271.

Cardozo, R.N. et al. (2002) 'Perspective: experiential education in new product design and business development', The Journal of Product Innovation Management, Vol. 19, No. 1, pp.4-17.

Carson, D., Gilmore, A., Gronhaug, K. and Perry, C. (2001) Qualitative Research in Marketing, Sage Publications, London.

Cassell, C. and Symon, G. (1994) Qualitative Methods in Organisational Research, Sage Publications, London.

Chonko, L.B., Howell, R.D. and Bellenger, D. (1986) 'Congruence in sales force evaluations: relation to sales force perceptions of conflict and ambiguity', Journal of Personal Selling and Sales Management, Vol. 6, No. 1, pp.35-48.

Choudhrie, J., Papazafeiropoulou, A. and Lee, H. (2003) 'A web of stakeholders and strategies: a case of broadband diffusion in South Korea', Journal of Information Technology, Vol. 18, No. 4, pp.281-90.

Cooper, L., Orrell, J. and Bowden, M. (2011) Work Integrated Learning: A Guide to Effective Practice, Routledge, New York.

Davenport, S., Davies, J. and Grimes, C. (1998) 'Collaborative research programmes: building trust from difference', Technovation, Vol. 19, No. 1, pp.31-40.

D'Este, P. and Patel, P. (2007) 'University-industry linkages in the UK: what are the factors underlying the variety of interactions with industry?', Research Policy, Vol. 36, No. 9, pp.1295-313.

Daniel, H.Z., Hempel, D.J. and Srinivasa, N. (2002) 'A model of value assessment in collaborative R\&D programs', Industrial Marketing Management, Vol. 31, No. 8, pp.653-664. 
Etzkowitz, H. and Leydesdorff, L. (1998) 'The endless transition: a 'triple helix' of university-industry-government relations', MINERVA, Vol. 36, No. 3, pp.203-208.

Etzkowitz, H. and Leydesdorff, L. (2000) 'The dynamics of innovation: from national systems and 'mode 2' to a triple helix of university-industry-government relations', Research Policy, Vol. 29, No. 2, pp.109-123.

Ford, N.M., Walker Jr., O. and Churchill Jr., G. (1975) 'Expectation-specific measures of the intersender conflict and role ambiguity experienced by industrial salesmen', Journal of Business Research, Vol. 3, No. 2, pp.95-112.

Freestone, R., Williams, P., Thompson, S. and Trembath, K. (2007) 'A quantitative approach to assessment of work-based learning outcomes: an urban planning application', Higher Education Research and Development, Vol. 26, No. 4, pp.347-361.

Fukuda, K. and Watanabe, C. (2008) 'Japanese and US perspectives on the national innovation ecosystem', Technology in Society, Vol. 30, No. 1, pp.49-63.

Galliers, R.D. (1990) 'Choosing appropriate information systems research approaches: a revised taxonomy', in Nissen, H.E., Klein, H.K. and Hirscheheim, R. (Eds.): The Information Systems Research Arena of the 90's, Perceptions and Alternative Approaches, pp.155-173, Blackwell Scientific, Copenhagen.

Garrett-Jones, S., Turpin, T., Burns, P. and Diment, K. (2005) 'Common purpose and divided loyalties: the risks and rewards of cross-sector collaboration for academic and government researchers', $R \& D$ Management, Vol. 35, No. 5, pp.535-544.

Groenewald, T. (2004) 'Towards a definition for cooperative education, in Coll, R.K. and Eames, C. (Eds.): International Handbook for Cooperative Education: An International Perspective of the Theory, Research and Practice of Work-Integrated Learning, World Association for Cooperative Education, Boston, pp.17-25.

Groot, T. and García-Valderrama, T. (2006) 'Research quality and efficiency: an analysis of assessments and management issues in Dutch economics and business research programs', Research Policy, Vol. 35, No. 9, pp.1362-1376.

Hargadon, A. and Sutton, R.I. (1997) 'Technology brokering and innovation in a product development firm', Administrative Science Quarterly, Vol. 42, No. 4, pp.718-749.

Harmon, B., Ardishvili, A., Cardozo, R., Elder, T., Leuthold, J., Parshall, J., Raghian, M. and Smith, D. (1997) 'Mapping the university technology transfer process', Journal of Business Venturing, Vol. 12, No. 6, pp.423-434.

Harryson, S., Kliknaite, S. and Dudkowski, R. (2007) 'Making innovative use of academic knowledge to enhance corporate technology innovation impact', The International Journal of Technology Management, Vol. 39, Nos. 1/2, pp.131-156.

Heikkinen, M.T., Mainela, T., Still, J. and Tahtinen, J. (2007) 'Roles for managing in mobile service development nets', Industrial Marketing Management, Vol. 36, No. 7, pp.909-925.

Howells, J. (2006) 'Intermediation and the role of intermediaries in innovation', Research Policy, Vol. 35, No. 5, pp.715-728.

Innovate America (2004) 'Innovate America: thriving in a world of challenge and change: National Innovation Initiative Summit and Report', Council on Competitiveness, Washington DC.

Jackson, D.J.J. (2013) What is an Innovation Ecosystem, National Science Foundation, Arlington VA [online] http://www.urenio.org/wp-content/uploads/2011/05/What-is-an-InnovationEcosystem.pdf (accessed 26 November 2013).

Katula, R.A. and Threnhauser, E. (1999) 'Experiential education in the undergraduate curriculum', Communication Education, Vol. 48, No. 3, pp.238-255.

Knemeyer, A.M. and Murphy, P.R. (2001) 'Logistic internships: employer and student perspectives', International Journal of Physical Distribution \& Logistics Management, Vol. 32, No. 2, pp.135-152.

Kolb, A.Y. and Kolb, D.A. (2005) 'Learning styles and learning spaces: enhancing experiential learning in higher education', Academy of Management Learning \& Education, Vol. 4, No. 2 , pp.193-212. 
Kuratko, D.F. (2005) 'The emergence of entrepreneurship education: development, trends and challenges', Entrepreneurship, Theory and Practice, Vol. 27, No. 5, pp.577-597.

Lee, Y.S. (1996) 'Technology transfer and the research university: a search for the boundaries for university-industry collaboration', Research Policy, Vol. 25, No. 6, pp.843-863.

Lucas, W.A., Cooper, S.Y., Ward, T. and Cave, F. (2009) 'Industry placement, authentic experience and the development of venturing and technology self-efficacy', Technovation, Vol. 29, No. 11, pp.738-752.

Lynn, L.H., Reddy, N.M. and Aram, J.D. (1996) 'Linking technology and institutions: the innovation community framework', Research Policy, Vol. 25, No. 1, pp.91-106.

Makkonnen, T. (2013) 'Government science and technology budgets in times of crisis', Research Policy, Vol. 42, No. 3, pp.817-822.

McEvily, B. and Zaheer, A. (1999) 'Bridging ties: a source of firm heterogeneity in competitive capabilities', Strategic Management Journal, Vol. 20, No. 12, pp.1133-1156.

McLennan, B. and Keating, S. (2008) 'Work-integrated learning (WIL) in Australian universities: the challenges of mainstreaming WIL', ALTC NAGCAS National Symposium.

Miles, M.B. and Huberman, A.M. (1994) An Expanded Sourcebook: Qualitative Data Analysis, Sage Publications, London.

Minzberg, H. (1973) The Nature of Managerial Work, Harper and Row, New York.

Moenaert, R.K., Caeldries, F., Lievens, A. and Wauters, E. (2000) 'Communication flows in international product innovation teams', Journal of Product Innovation Management, Vol. 17, No. 5, pp.360-377.

Mohr, J.J., Fisher, R.J. and Nevin, J.R. (1996) 'Collaborative communication in interfirm relationships: moderating effects of integration and control', Journal of Marketing, Vol. 60, No. 3, pp.103-115.

Morandi, V. (2013) 'The management of industry-university joint research projects: how do partners coordinate and control R\&D activities?', Journal of Technology Transfer, Vol. 38, No. 2, pp.69-92.

Motohashi, K. (2013) 'University-industry collaborations in Japan: the role of new technology-based firms in transforming the national innovation system', Research Policy, Vol. 34, No. 5, pp.583-594.

Narayanan, V.K. and Olk, P.M. (2010) 'Determinants of internship effectiveness: an exploratory model', Academy of Management Learning and Education, Vol. 9, No. 1, pp.61-80.

Netemeyer, R.G., Boles, J.S. and McMurrian, R. (1996) 'Development and validation of work-family and family-work conflict scales', Journal of Applied Psychology, Vol. 81, No. 4, pp.400-410.

Orrell, J. (2004) 'Work-integrated learning programmes: management and educational quality', Proceedings of the Australian Universities Quality Forum (AUGF).

Papakonstantinou, T., Charlton-Robb, K., Reina, R.D. and Rayne, V. (2013) 'Providing research-focused work-integrated learning for high achieving science undergraduates', Asia-Pacific Journal of Cooperative Education, Vol. 14, No. 2, pp.59-73.

Patrick, C.J., Peach, D. and Pocknee, C. (2009) The WIL [Work Integrated Learning] Report: A National Scoping Study, Final report to the Australian Learning and Teaching Council (ALTC).

Patton, M.Q. (1990) Qualitative Evaluation and Research Methods, Sage Publications, London.

Perkmann, M. et al. (2013) 'Academic engagement and commercialisation: a review of the literature on university-industry relations', Research Policy, Vol. 42, No. 2, pp.423-442.

Perkmann, M., Neely, A. and Walsh, K. (2011) 'How should firms evaluate success in university-industry alliances? A performance measurement system', R\&D Management, Vol. 41, No. 2, pp.202-216. 
Plewa, C. and Quester, P. (2007) 'Key drivers of university-industry relationships: the role of organisational compatibility and personal experience', Journal of Services Marketing, Vol. 21, No. 5, pp.370-82.

Plewa, C., Baaken, T., Macpherson, G., Korff, N., Johnson, C. and Rampersad, G.C. (2013) 'The evolution of university-industry linkages: a framework', Journal of Engineering and Technology Management, Vol. 30, No. 1, pp.21-44.

Popp, A. (2000) 'Swamped in information but starved of data': information and intermediaries in clothing supply chains', Supply Chain Management, Vol. 5, No. 3, pp.151-161.

Rampersad, G., Quester, P. and Troshani, I. (2009) 'Management of networks involving technology transfer from public to private sector: a conceptual framework', International Journal of Technology Transfer and Commercialisation, Vol. 8, Nos. 2/3, pp.121-41.

Rampersad, G.C., Quester, P. and Troshani, I. (2010) 'Managing innovation networks: exploratory evidence from ICT, biotechnology and nanotechnology networks', Industrial Marketing Management, Vol. 39, No. 5, pp.793-805.

Reeders, E. (2000) 'Scholarly practice in work-based learning: fitting the glass slipper', Higher Education Research \& Development, Vol. 19, No. 2, pp.205-220.

Rizzo, J.R., House, R.J. and Lirtzman, S.I. (1970) 'Role conflict and ambiguity in complex organisations', Administrative Science Quarterly, Vol. 15, No. 2, pp.150-164.

Rose, E., McKee, W., Temple, B.K., Harrison, D.K. and Kirkwood, D. (2001) 'Workplace learning: a concept in off campus teaching', The Learning Organisation, Vol. 8, No. 2, pp.70-77.

Rounce, K., Scarfe, A. and Garnett, J. (2007) 'A work-based learning approach to developing leadership for senior health and social care professionals: a case study from Middlesex University', Education \& Training, Vol. 49, No.3, pp.218-226.

Schuurman, M.K., Pangborn, R.N. and McClintic, R.D. (2013) 'Assessing the impact of engineering undergraduate work experience: factoring in pre-work academic performance', Journal of Engineering Education, Vol. 2, No. 2, pp.207-212.

Siegel, D.S., Thursby, J.G., Thursby, M.C. and Ziedonis, A.A. (2001) 'Organisational issues in university-industry technology transfer: An overview of the symposium issue', Journal of Technology Transfer, Vol. 26, Nos. 1-2, pp.5-11.

Siegel, D.S., Waldman, D.A., Atwater, L.E. and Link, A.N. (2003) 'Commercial knowledge transfers from universities to firms: improving the effectiveness of university - industry collaboration', Journal of High Technology Management Research, Vol. 14, No. 1, pp.111-133.

Singh, J. and Rhoads, G.K. (1991) 'Boundary role ambiguity in marketing-oriented positions: a multidimensional, multifaceted operationalisation', Journal of Marketing Research, Vol. 28, No. 3, pp.328-338.

Smith, A.M. and Fischbacher, M. (2005) 'New service development: a stakeholder perspective', European Journal of Marketing, Vol. 39, Nos. 9/10, pp.1025-1048.

Sobiechowska, P. and Maisch, M. (2007) 'Work-based learning and continuing professional development', Education and Training, Vol. 49, No. 3, pp.182-192.

Stephan, P.E. (2001) 'Educational implications of university-industry technology transfer', Journal of Technology Transfer, Vol. 26, No. 3, pp.199-205.

Turpin, T. and Deville, A. (1995) 'Occupational roles and expectations of research scientists and research managers in scientific research institutions', $R \& D$ Management, Vol. 25, No. 2, pp.141-157.

Turpin, T., Garrett-Jones, S. and Rankin, N. (1996) 'Bricoleurs and boundary riders: managing basic research and innovation knowledge networks', R\&D Management, Vol. 26, No. 3, pp.267-282.

van de Ven, A.H. (1976) 'On the nature, formation, and maintenance of relations among organisations', Academy of Management Review, Vol. 1, No. 4, pp.24-36. 
von Hippel, E. (2009) 'Democratizing innovation: the evolving phenomenon of user innovation', International Journal of Innovation Science, Vol. 1, No. 1, pp.29-40.

Wilson, T. (2012) A Review of Business-University Collaboration, Department for Business, Innovation and Skills, Government of the United Kingdom, UK.

Wright, M., Clarysse, B., Lockett, A. and Knockaert, M. (2008) 'Mid-range universities' linkages with industry: knowledge types and the role of intermediaries', Research Policy, Vol. 37, No. 8, pp.1205-1223.

Yin, R.K. (1994) Case Study Research: Design and Methods, Sage Publications, Beverley Hills. 